\title{
Insights into Molecular Interaction of Flavonoid Compounds in Citrus Peel Bound to Collagenase and Elastase Enzymes: A Computational Study
}

\author{
Sani Ega Priani*, Taufik Muhammad Fakih \\ Department of Pharmacy, Faculty of Mathematics and Natural Sciences, Universitas Islam Bandung, Bandung, Indonesia
}

\begin{abstract}
Citrus peels contain various phytochemical active compounds such as flavonoids that are useful for antiaging cosmetic products. This study was conducted to identify the anti-collagenase and anti-elastase activities of flavonoid compounds in citrus peel and to determine the molecular interaction mechanism using the molecular docking method. The study was carried out through several stages, including preparation of enzyme macromolecules, preparation of flavonoid compound molecules, validation of molecular docking, identification of binding-free energy, visualization of interaction conformations, and predictions of molecular skin toxicity. The result showed that the flavonoid compounds in citrus peel (hesperidin, naringin, nobiletin, and tangeretin) could bind to collagenase and elastase enzymes. Naringin has the highest affinity for the collagenase enzyme with the binding-free energy of $-9.52 \mathrm{kcal} /$ mol, while nobiletin has the highest affinity for the elastase enzyme with the binding-free energy of $-6.44 \mathrm{kcal} / \mathrm{mol}$. Compared to EGCG (epigallocatechin gallate), the flavonoid compounds have a lower affinity for the collagenase enzyme but a higher affinity for elastase enzymes. Hydrogen bonds and the hydrophobic interactions dominate the interaction between citrus peel's flavonoids against the enzymes. When applied to the skin, flavonoid compounds are predicted to have no risk of skin toxicity. The flavonoid compounds of citrus peels are expected to have anti-collagenase and anti-elastase activities.
\end{abstract}

Keywords: citrus peel; flavonoid; elastase; collagenase; in silico

*corresponding author

Email: egapriani@gmail.com

\section{INTRODUCTION}

Skin aging is a complex biological process that can occur due to intrinsic (genetics, cellular metabolism, and hormone) and extrinsic (chronic sun exposure, pollution, and radiation) factors (Ganceviciene et al., 2012). Intrinsic skin aging is caused by changes in the elasticity of the skin over time. Extrinsic skin aging is predominately a result of chronic ultraviolet (UV) exposure. Excessive UV exposure significantly increases reactive oxygen species (ROS) formation (Singh et al., 2018). ROS can initiate complex molecular pathways, including degradation of extracellular matrix (ECM) biomolecules such as collagen and elastin (Eun Lee et al., 2019).

Collagen is the most abundant protein in the ECM and is responsible for the skin's elasticity, strength, and flexibility. Elastin is a vital protein for maintaining skin elasticity and resilience (Osorio et al., 2019). Reduction in collagen and elastin leads to wrinkling skin formation. Collagenase and elastase enzymes are responsible for breaking those biomolecules (Apraj \& Pandita, 2016). Active compounds that can inhibit the collagenase and elastase enzyme's act can be used in antiaging cosmetic products (Azmi et al., 2014).
Many natural resources are known to have anticollagenase and anti-elastase activities. Secondary metabolites such as polyphenols and flavonoids are known to support those activities. For example, the polyphenol compounds extracted from tea leaves, such as catechin, and epigallocatechin gallate (EGCG), are known to have potent anti-collagenase and anti-elastase activities (Thring et al., 2009). The flavonoid compounds in several plant extracts, including Aloe barbadensis, Diospyros feet, Hylocereus sp., Lansium domesticum, are proven to have similar activities (Vijayakumar et al., 2017). Another natural resource, known to contain many polyphenol and flavonoid compounds and the potential to have anti-collagenase and anti-elastase activities, is the citrus peel.

Citrus is one of the world's most popular fruit plants, containing many active compounds that are good for health (Lv et al., 2015). The production of citrus (orange) in Indonesia is very high. According to the data, it is known that in 2020, the production of citrus in Indonesia can reach 3 million tons a year (Fitri \& Widyastuti, 2020). The high production and consumption of citrus fruit cause a high level of waste. Citrus peel has not been used optimally, even though several studies have shown many beneficial peel compounds (Gómez-Mejía et al., 2019). 
Citrus peel is known to contain: essential oils (0.6$1 \%$ ), fiber (6.30-42.13\%), phenolic compounds (0.67$19.62 \%)$, and vitamin C (0.109-1.150\%) (M'hiri et al., 2017). The main phenolic compounds contained in citrus peels are flavanones glucoside (hesperidin and naringin) and polymethoxylated flavones (PMFs) (nobiletin and tangeretin) (Rafiq et al., 2018). The phenolic compounds from citrus fruit peels have many pharmacological activities such as antioxidants, anti-inflammatory, anticancer, anti-proliferative, anti-viral, and anti-platelet aggregation (Chen et al., 2017).

This study was conducted to identify the anti-collagenase and anti-elastase activities of flavonoid compounds in citrus peel (hesperidin, naringin, nobiletin, and tangeretin) and to determine the mechanism of molecular interactions. In addition, this study aimed to predict the risk of skin toxicity from citrus peel flavonoids. EGCG was used as a reference compound in this study. EGCG is known as one of the active compounds that has potent anti-collagenase and anti-elastase activities. Some studies used EGCG as a reference in anti-collagenase and antielastase activity tests (Thring et al., 2009). Identification, evaluation, and exploration of the molecular interactions between these compounds against the collagenase and elastase enzymes were carried out using the molecular docking method. A computational study for predicting bioactive compound's pharmacological activity is widely applied because it is relatively more effective, easy, fast, inexpensive, and reliable.

\section{METHODS}

\section{Matrix Metalloproteinase Macromolecules Preparation}

The matrix metalloproteinase macromolecules used were collagenase (MMP-8) and elastase (MMP-12) obtained from Protein Data Bank (http://www.rcsb.org/ pdb) with PDB ID 5H8X (with a resolution of $1.30 \AA$ )

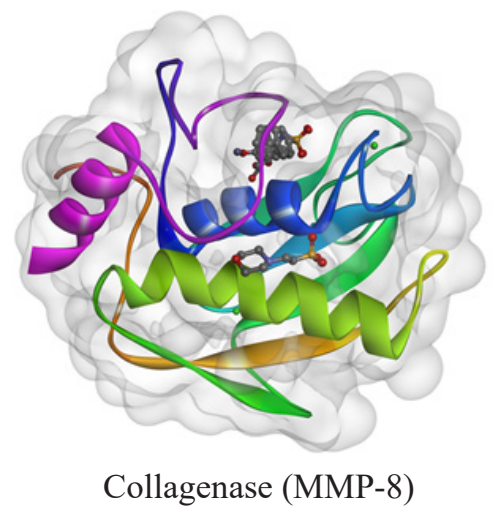

and PDB ID 5A8X (with a resolution of $2.23 \AA$ ) (Figure 1) (Tauro et al., 2016; Von Nussbaum et al., 2016). The two matrix metalloproteinase macromolecules were then prepared by removing water molecules, catechol (as the original ligand of collagenase) and dihydropyrimidone (as the original ligand of elastase), adding polar hydrogen atoms, and calculating Kollman's partial charge (Ugur et al., 2014).

\section{Flavonoid Compound Molecules Preparation}

The flavonoid compound molecules used were hesperidin, naringin, nobiletin, and tangeretin, which were contained in citrus peel. The EGCG structure molecule acts as a reference for the flavonoid compound's four molecules. EGCG is known as one of the active compounds that have potent anti-collagenase and anti-elastase activities. Some studies used EGCG as a reference in anti-collagenase and anti-elastase activity tests (Thring et al., 2009). The compound's entire molecular structure was modelled in the form of a three-dimensional conformation, and then the optimization used a semi-empirical method based on the AM1 basis set (Figure 2). The flavonoid and EGCG compound molecules that had been modelled and optimized were then modified on partial charge data to be used as input in the molecular docking simulation (Muttaqin et al., 2017).

\section{Molecular Docking Validation}

The validation of the molecular docking method had to be done first using MGLTools 1.5.6 with AutoDock 4.2 to determine some of the parameters used in the molecular docking simulation between all the molecules of the flavonoid compound and EGCG towards the matrix metalloproteinase macromolecules. Validation of this molecular docking method was done by re-docking the original ligand. In this re-docking process, the parameters are declared to meet the criteria if the Root Mean Square Deviation (RMSD) value does not exceed the maximum distance of $2 \AA$ (Zhu et al., 2014).

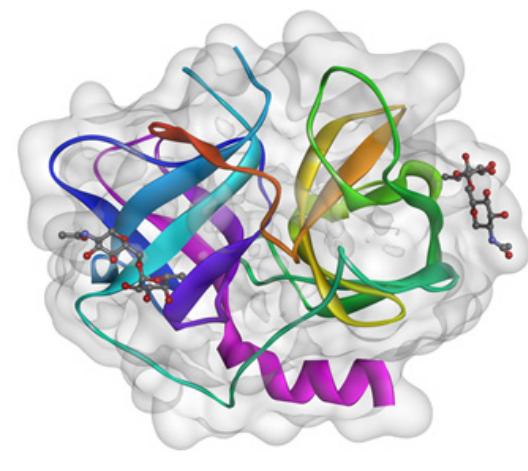

Elastase (MMP-12)

Figure 1. The matrix metalloproteinase macromolecules structure (Tauro et al., 2016; Von Nussbaum et al., 2016) 


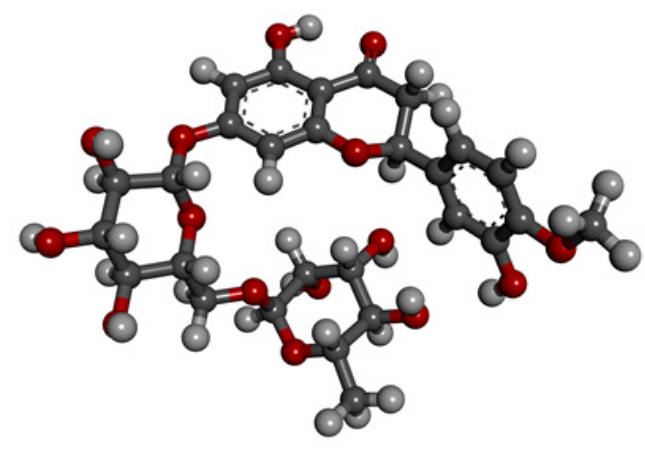

Hesperidin

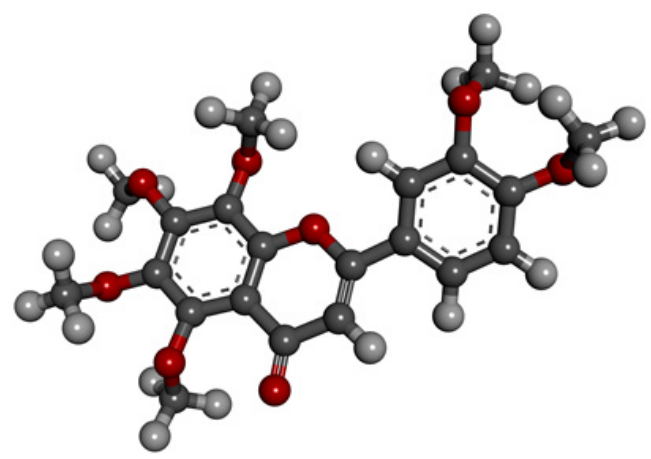

Nobiletin

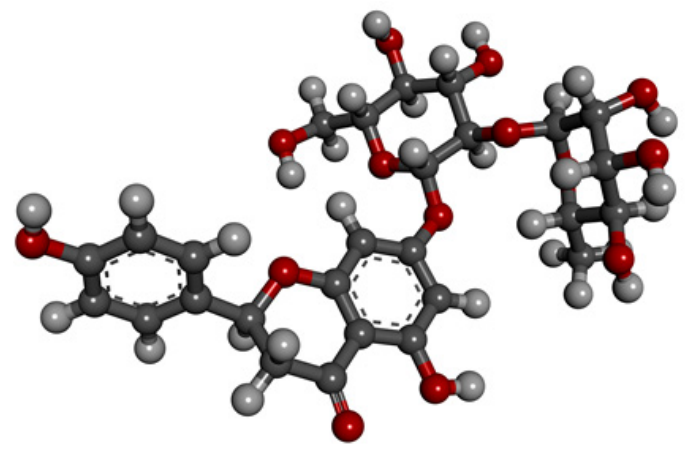

Naringin

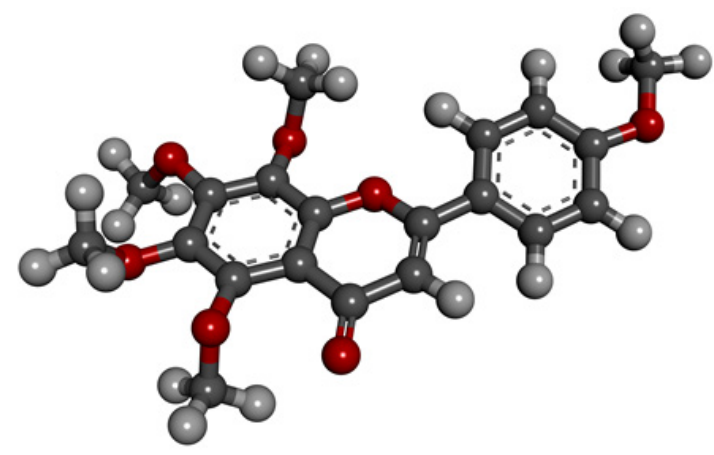

Tangeretin

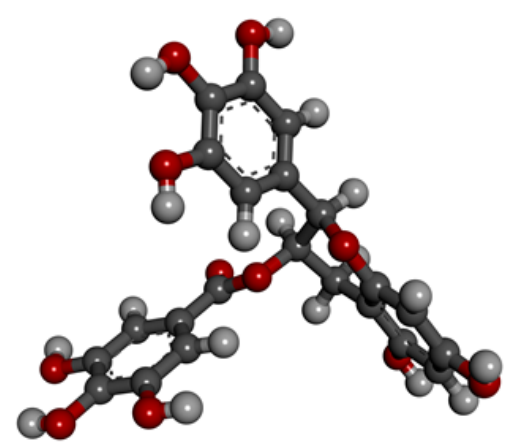

Epigallocatechin gallate (EGCG)

Figure 2. The three-dimensional compound molecules structure (Kim et al., 2021)

\section{Molecular Docking Simulations}

Molecular docking simulations were accomplished using MGLTools 1.5.6 with AutoDock 4.2. The molecular compounds of flavonoids and EGCG for molecular docking simulations were modelled and optimized, then added with hydrogen atoms and Gasteiger's partial charge. The distance between the surface area of the matrix metalloproteinase macromolecules and the compound molecules was limited to the maximum radius limit of $0.375 \AA$. The shape of the Connolly point surface of the molecule into different components, including convex, concave, and flat patches, was generated through the AutoDock 4.2 algorithm. All molecular docking simulations were demonstrated using a grid box measuring 64 × $60 \times 60$ and the Lamarckian Genetic
Algorithm method with 100 conformations. The size limitation of the grid box is intended to prevent changes in the relative orientation of the compound molecules and the flexibility of the interacting surface's side chains is intended to allow the movement of small and rigid molecules (Forli et al., 2016).

\section{Binding-Free Energy Result Identification}

The results obtained from the molecular docking simulation were then observed, identified, and evaluated for the affinity of each molecule of the flavonoid and EGCG compounds based on the value of binding-free energy and inhibition constants through molecular interactions formed on matrix metalloproteinase macromolecules (Mobley \& Klimovich, 2012). 
Table 1. The total energy and the GAP energy values of the geometry optimization results

\begin{tabular}{lll}
\hline Compound molecule & Total energy (a.u) & GAP energy (a.u) \\
\hline Hesperidin & -0.97 & 0.30 \\
Naringin & -0.91 & 0.32 \\
Nobiletin & -0.32 & 0.30 \\
Tangeretin & -0.27 & 0.30 \\
Epigallocatechin gallate (EGCG) & -0.61 & 0.30 \\
\hline
\end{tabular}

\section{Interaction Conformation Visualization}

The amino acid residues, that played a role in the molecular interactions, formed were then observed using BIOVIA Discovery Studio 2020. Some of these molecular interactions include hydrogen bonds, hydrophobic interactions, and electrostatic interactions. Molecular interactions between flavonoid and EGCG compound molecules against collagenase and elastase enzymes can illustrate small molecular ligand's ability to stabilize the active binding sites of target macromolecules (Dar \& Mir, 2017)

\section{Molecular Skin Toxicity Prediction}

Toxicity prediction was performed to observe the effects of flavonoid and EGCG molecules on the skin surface using Toxtree v.3.1.0. Two parameters were used to predict toxicity at this stage, namely Skin Irritation/ Corrosion and Skin Sensitization Reactivity Domain. Skin Irritation/Corrosion is a parameter that can be used to assess the potential for irritation or corrosion or a combination of both of the molecular compound structures. Then Skin Sensitization Reactivity Domains are used to determine the sensitivity of compound molecules in the surface area of the skin contact (Han et al., 2019).

\section{RESULTS AND DISCUSSION}

\section{Total Energy Calculation of Compound Molecules} Optimization

Modelling and geometry optimization were demonstrated on hesperidin, naringin, nobiletin, tangeretin, and EGCG compound molecules in the form of three-dimensional structures using the semi-empirical method based on the AM1 basis set. The five compound molecule's geometry optimization results with the best conformation were selected based on the total energy value and the difference between Highest Occupied Molecular Orbital-Lowest Unoccupied Molecular Orbital (HOMO-LUMO) (GAP energy).

Based on the results of the optimization of the molecular geometry of compounds listed in Table 1, flavonoids and EGCG had good total energy and GAP energy values and could be predicted to be able to interact well at the active site of the target macromolecule binding site (Bakalova $\&$ Kaneti, 2000). The total energy and GAP energy were generated to describe the conformation of the molecular structure of flavonoids and EGCG compounds that had approached their original state and were expected to form stable molecular interactions with target macromolecules. All flavonoid molecular structures that had been energy minimized were then verified for their partial charge as input in molecular docking simulations.

Binding Affinity of Molecular Compounds Structure The molecular compounds of flavonoids and EGCG that had been modelled and optimized were then identified, evaluated, and compared to their affinity and molecular interaction capabilities on matrix metalloproteinase macromolecules prepared through molecular docking simulations using MGLTools 1.5.6 with AutoDock 4.2. This simulation was accomplished using several methods that had been validated in the previous stage. Based on the validation of the molecular docking method, the RMSD values were $0.50 \AA$ (MMP-8) and $0.83 \AA$ (MMP-12). Validation of the docking method is declared valid and can be used if the RMSD is less than $2 \AA$. This RMSD value can show the closeness of the original ligand conformation before and after the re-docking process (Pitaloka et al., 2021). Some of the parameters used were the size of the grid box, the number of conformations, and the maximum value of the conformation search evaluation.

The molecular docking simulation results in Table 2 show that all flavonoid compounds from citrus peels have an affinity for binding with collagenase and elastase enzymes. Naringin has the best affinity with the active binding site of collagenase (MMP-8) compared to other flavonoid compound molecules, with the bindingfree energy value of $-9.52 \mathrm{kcal} / \mathrm{mol}$. Nevertheless, compared to the original ligand and EGCG, the flavonoid compounds of citrus peel have a lower affinity for the collagenase enzyme (Fakih \& Dewi, 2020).

A different phenomenon is shown when all the molecular compounds interact with elastase (MMP-12). The 
Table 2. The affinity of the molecular docking simulations

\begin{tabular}{llll}
\hline Macromolecule receptor & Compound molecule & Binding-free energy (kcal/mol) & Inhibition constant \\
\hline Collagenase (MMP-8) & Original ligand & -11.50 & $3.70 \mathrm{nM}$ \\
& Hesperidin & -8.83 & $334.47 \mathrm{nM}$ \\
& Naringin & -9.52 & $105.51 \mathrm{nM}$ \\
& Nobiletin & -8.73 & $400.02 \mathrm{nM}$ \\
& Tangeretin & -8.79 & $359.11 \mathrm{nM}$ \\
& Epigallocatechin gallate & -9.93 & $52.57 \mathrm{nM}$ \\
& (EGCG) & & \\
\hline Elastase (MMP-12) & Original ligand & -9.67 & $81.93 \mathrm{nM}$ \\
& Hesperidin & -6.16 & $30.12 \mathrm{uM}$ \\
& Naringin & -6.17 & $19.06 \mathrm{uM}$ \\
& Nobiletin & -6.44 & $42.93 \mathrm{uM}$ \\
& Tangeretin & -5.96 & $49.48 \mathrm{uM}$ \\
& Epigallocatechin gallate & -5.87 & $32.79 \mathrm{uM}$ \\
& (EGCG) & & \\
\hline
\end{tabular}
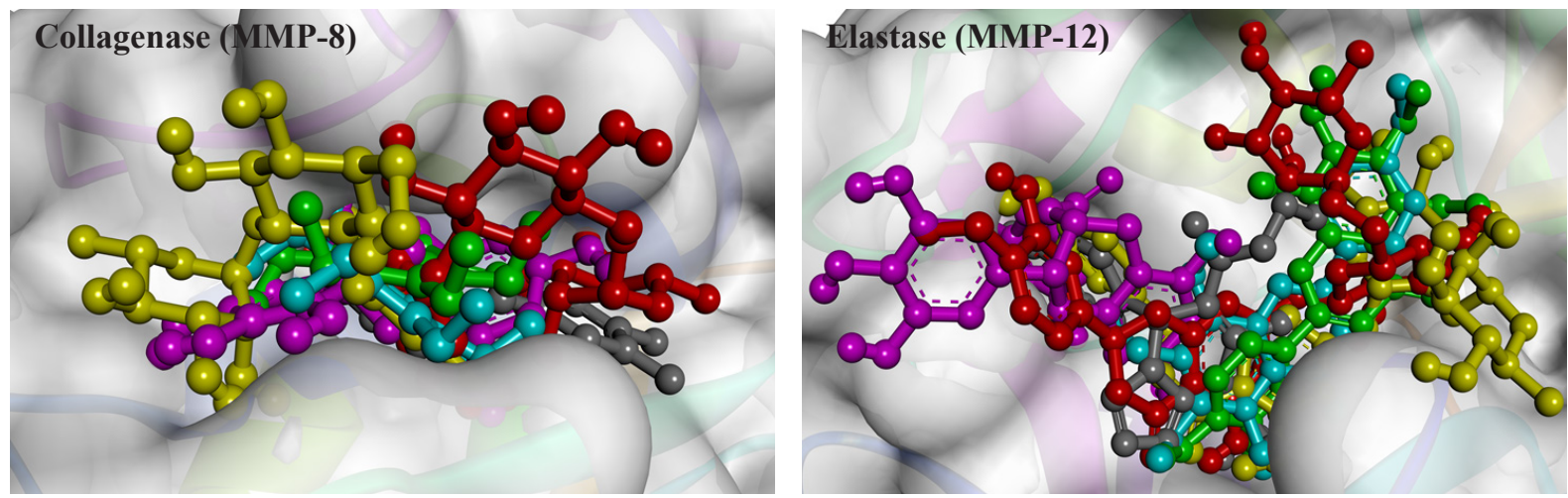

$\square$ Original ligand, $\square$ Hesperidin, $\square$ Naringin, $\square$ Nobiletin, $\square$ Tangeretin, $\square$ Epigallocatechin gallate (EGCG)

Figure 3. The overlay conformations of compound molecules in the binding-site area of macromolecules

flavonoid compound molecules have a better affinity to elastase enzyme than EGCG. Thus, hesperidin, naringin, nobiletin, and tangeretin are predicted to have the potential as elastase inhibitors (MMP-12). The result of molecular docking simulations shows that nobiletin has the best binding-free energy value of $-6.44 \mathrm{kcal} /$ mol with the elastase enzyme. However, similarly when interacting with collagenase (MMP-8), all compounds have binding-free energy that is not better than original ligands.

\section{Conformational Modes in the Binding-Site Area}

Based on the visualization of the active binding sites for each target macromolecule, in general, hesperidin, naringin, nobiletin, and tangeretin showed conformational similarities to the EGCG compound molecule as a reference (Figure 3). Most of the compound molecules are able to interact with amino acid residues Leu160, Ala161, Ala163, Leu193, Val194, His197, and His201 on collagenase (MMP-8). They are able to interact also with amino acid residues in the active site area of elastase
(MMP-12), including His57, Leu99, Val190, Cys191, Phe192, Asp194, Ser195, Ala213, Ser214, Phe215, and Val216. This phenomenon can occur because the AutoDock 4.2 algorithm supports small molecules of compounds to move freely without rigid bonds with the molecular docking methods used.

The interaction between flavonoid and EGCG compound molecules against the two matrix metalloproteinase macromolecules is dominated by hydrogen bonds and the formed hydrophobic interactions (Table 3). Significantly, the EGCG compound molecule has electrostatic interactions with Glu198 (in collagenase (MMP-8)) and Asp102 (in elastase (MMP-12)). Importantly, the original ligands found in elastase (MMP-12) can bind firmly to the active site due to the contribution of halogen interactions with several amino acid residues, including Cys191, Asp194, Ser195, Ala213, Ser214, and Phe215. It is predicted that this makes the interactions of each original ligand and EGCG against the enzymes more stable. 
Table 3. The molecular interactions of molecular docking simulation

\begin{tabular}{|c|c|c|c|}
\hline $\begin{array}{l}\text { Macromolecule } \\
\text { receptor }\end{array}$ & Compound molecule & Type of interactions & Amino acid residues \\
\hline \multirow{14}{*}{$\begin{array}{l}\text { Collagenase } \\
(\mathrm{MMP}-8)\end{array}$} & \multirow[t]{3}{*}{ Original ligand } & Hydrogen bond & Ile159, Leu160, Ala161, Ala163 \\
\hline & & Hydrophobic interaction & Leu160, Leu193, Val194, His197 \\
\hline & & Electrostatic interaction & Glu198 \\
\hline & \multirow[t]{2}{*}{ Hesperidin } & Hydrogen bond & $\begin{array}{l}\text { Leu160, Ala161, Glu198, Asn218, } \\
\text { His201, His207 }\end{array}$ \\
\hline & & Hydrophobic interaction & Ile159, Leu160, Val194, His 197 \\
\hline & \multirow[t]{2}{*}{ Naringin } & Hydrogen bond & $\begin{array}{l}\text { Gly158, Leu160, Ala161, Tyr189, } \\
\text { Asn218, Tyr219 }\end{array}$ \\
\hline & & Hydrophobic interaction & $\begin{array}{l}\text { Leu160, Tyr189, Val194, His197, } \\
\text { Tyr219 }\end{array}$ \\
\hline & \multirow[t]{2}{*}{ Nobiletin } & Hydrogen bond & $\begin{array}{l}\text { Gly158, Ala213, Leu214, Tyr216, } \\
\text { Pro217, Asn218, Tyr219, Ala220 }\end{array}$ \\
\hline & & Hydrophobic interaction & Leu160, Val194, His197, Tyr219 \\
\hline & \multirow[t]{2}{*}{ Tangeretin } & Hydrogen bond & Ile159, Gly158, Tyr219, Ala220 \\
\hline & & Hydrophobic interaction & Leu160, Val194, His197, Tyr219 \\
\hline & \multirow[t]{3}{*}{$\begin{array}{l}\text { Epigallocatechin gallate } \\
\text { (EGCG) }\end{array}$} & Hydrogen bond & $\begin{array}{l}\text { Gly158, Leu160, Ala161, Tyr189, } \\
\text { Tyr219, Ala220 }\end{array}$ \\
\hline & & Hydrophobic interaction & Leu160, His 197 \\
\hline & & Electrostatic interaction & Glu198 \\
\hline \multirow{14}{*}{$\begin{array}{l}\text { Elastase } \\
(\mathrm{MMP}-12)\end{array}$} & \multirow[t]{3}{*}{ Original ligand } & Hydrogen bond & Ser195, Phe215, Val216 \\
\hline & & Hydrophobic interaction & $\begin{array}{l}\text { His57, Leu99, Val190, Phe192, } \\
\text { Ala213, Val216 }\end{array}$ \\
\hline & & Halogen interaction & $\begin{array}{l}\text { Cys191, Asp194, Ser195, Ala213, } \\
\text { Ser214, Phe215 }\end{array}$ \\
\hline & \multirow[t]{2}{*}{ Hesperidin } & Hydrogen bond & $\begin{array}{l}\text { Phe41, His57, Ala60, Pro96, } \\
\text { Ser195, Val216 }\end{array}$ \\
\hline & & Hydrophobic interaction & Leu99, Phe192 \\
\hline & \multirow[t]{2}{*}{ Naringin } & Hydrogen bond & $\begin{array}{l}\text { Phe41, His57, Pro96, Phe192, } \\
\text { Gly193, Ser214, Val216 }\end{array}$ \\
\hline & & Hydrophobic interaction & His57, Leu99, Phe192, Leu143 \\
\hline & \multirow[t]{2}{*}{ Nobiletin } & Hydrogen bond & His57, Ala60, Gly193, Ser195, Val216 \\
\hline & & Hydrophobic interaction & His57 \\
\hline & \multirow[t]{2}{*}{ Tangeretin } & Hydrogen bond & $\begin{array}{l}\text { His } 57, \text { Phe192, Ser195, } \\
\text { Ser214, Val216 }\end{array}$ \\
\hline & & Hydrophobic interaction & Phe192 \\
\hline & \multirow{3}{*}{$\begin{array}{l}\text { Epigallocatechin gallate } \\
\text { (EGCG) }\end{array}$} & Hydrogen bond & His57, Tyr94, Va197, Leu100, Ser214 \\
\hline & & Hydrophobic interaction & His57, Leu99 \\
\hline & & Electrostatic interaction & Asp102 \\
\hline
\end{tabular}


Table 4. The skin toxicity prediction of compound molecules

\begin{tabular}{lll}
\hline Compound molecule & Skin Irritation / Skin Corrosion & Skin Sensitization Reactivity Domains \\
\hline Hesperidin & Not corrosive to skin & No skin sensitization reactivity \\
Naringin & Not corrosive to skin & No skin sensitization reactivity \\
Nobiletin & Not corrosive to skin & No skin sensitization reactivity \\
Tangeretin & Not corrosive to skin & No skin sensitization reactivity \\
$\begin{array}{l}\text { Epigallocatechin gallate } \\
(\text { EGCG) }\end{array}$ & Not corrosive to skin & No skin sensitization reactivity \\
\hline
\end{tabular}

In molecular docking simulations, the most responsible complex molecular interactions are hydrogen bonds, especially the flavonoid and EGCG compounds, which act as hydrogen bond donors, and amino acid residues on matrix metalloproteinase macromolecules, which act as hydrogen bond acceptors. Most hydrogen bonds are relatively strong, with average bond lengths less than 3 $\AA$ (Boyken et al., 2016). Apart from hydrogen bonding, there are also contributions from hydrophobic and electrostatic interactions that play a role in stabilizing small molecular ligand's flexibility on the active sites of target macromolecules.

\section{Skin Toxicity of Compound Molecules Prediction}

The prediction of molecular toxicity in the surface area of the skin contact from hesperidin, naringin, nobiletin, tangeretin, and EGCG, was accomplished using two parameters, namely Skin Irritation/Corrosion and Skin Sensitization Reactivity Domain. Skin Irritation/ Corrosion is a parameter that can assess whether a compound's molecular structure has the potential to cause irritation or corrosion or a combination of both. Furthermore, Skin Sensitization Reactivity Domains are used to determine the sensitivity of compound molecules to areas that have direct contact with the skin surface (Deshmukh et al., 2012).

In this case, it is important to carry out toxicity testing to estimate the degree of damage caused by a compound to biological or non-biological materials. Toxicological screening is essential in developing new drugs and determining the therapeutic potential of a drug molecule. Toxicity testing is generally intended to determine the undesirable effects of a drug, especially on the incidence of cancer, heart disorders, and skin or eye irritation. Some herbal bioactive compounds are known to have a risk of skin irritation (Seitz et al., 2013; Xu et al., 2020).

Based on the results of the skin toxicity prediction in Table 4, it was found that the flavonoid and EGCG compound molecules had less potential to cause irritation or corrosion on the skin surface. This category of irritation or corrosion indicates that the compound's molecular structure has a low risk of causing severe burns that can irritate the skin surface. Then, similar to the results of the Skin Irritation/Corrosion parameters in the previous stage, the molecules of flavonoids and EGCG were included in the low category in causing severe sensitivity to the skin surface based on the skin Sensitization Reactivity Domains parameter. Thus, the compound molecules are predicted to be safe for use as active compounds in topical preparation formulations.

\section{CONCLUSION}

Based on the study results, it can be concluded that the flavonoid compounds in citrus peel (hesperidin, naringin, nobiletin, and tangeretin) could bind to collagenase and elastase enzymes. Naringin has the highest affinity for the collagenase enzyme with the binding-free energy of $-9.52 \mathrm{kcal} / \mathrm{mol}$, while nobiletin has the highest affinity for the elastase enzyme with the binding-free energy of $-6.44 \mathrm{kcal} / \mathrm{mol}$. Compared with EGCG, flavonoid compounds have a lower affinity for the collagenase enzyme, but a higher affinity for elastase enzymes. When applied to the skin, flavonoid compounds are predicted to have no risk of skin toxicity.

\section{ACKNOWLEDGMENT}

The authors gratefully acknowledge the research grant support from LPPM UNISBA.

\section{CONFLICT OF INTEREST}

The authors have no conflict of interest to declare.

\section{REFERENCES}

Apraj, V. D., \& Pandita, N. S. (2016). Evaluation of skin antiaging potential of Citrus reticulata blanco peel. Pharmacognosy Research, 8(3): 160-168. https://doi. org/10.4103/0974-8490.182913

Azmi, N., Hashim, P., Hashim, D. M., Halimoon, N., \& Nik Majid, N. M. (2014). Anti-elastase, anti-tyrosinase 
and matrix metalloproteinase-1 inhibitory activity of earthworm extracts as potential new antiaging agent. Asian Pacific Journal of Tropical Biomedicine, 4(Suppl 1): S348-S352. https://doi.org/10.12980/ APJTB.4.2014C1166

Bakalova, S., \& Kaneti, J. (2000). Semi-empirical AM1 calculation of the solvent effect on the fluorescence spectra of some dihydroquinolinones. Spectrochimica Acta-Part A: Molecular and Biomolecular Spectroscopy, 56(8): 1443-1452. https://doi.org/10.1016/S13861425(99)00282-6

Boyken, S. E., Chen, Z., Groves, B., Langan, R. A., Oberdorfer, G., Ford, A., Gilmore, J. M., Xu, C., DiMaio, F., Pereira, J. H., Sankaran, B., Seelig, G., Zwart, P. H., \& Baker, D. (2016). De novo design of protein homo-oligomers with modular hydrogen-bond network-mediated specificity. Science, 352(6286): 680687. https://doi.org/10.1126/science.aad8865

Chen, X. M., Tait, A. R., \& Kitts, D. D. (2017). Flavonoid composition of orange peel and its association with antioxidant and anti-inflammatory activities. Food Chemistry, 218: 15-21. https://doi.org/10.1016/j. foodchem.2016.09.016

Dar, A. M., \& Mir, S. (2017). Molecular Docking: Approaches, Types, Applications and Basic Challenges. Journal of Analytical \& Bioanalytical Techniques, 8(2): 356. https://doi.org/10.4172/2155-9872.1000356

Deshmukh, G. R., Kumar, K. H., Reddy, P. V. S., \& Rao, B. S. (2012). In vitro skin corrosion: Human skin model test - A validation study. Toxicology in Vitro, 26(6): 1072-1074. https://doi.org/10.1016/j.tiv.2012.04.021

Eun Lee, K., Bharadwaj, S., Yadava, U., \& Gu Kang, S. (2019). Evaluation of caffeine as inhibitor against collagenase, elastase and tyrosinase using in silico and in vitro approach. Journal of Enzyme Inhibition and Medicinal Chemistry, 34(1): 927-936. https://doi.org/1 $0.1080 / 14756366.2019 .1596904$

Fakih, T. M., \& Dewi, M. L. (2020). Identifikasi Mekanisme Molekuler Senyawa Bioaktif Peptida Laut sebagai Kandidat Inhibitor Angiotensin-I Converting Enzyme (ACE). Jurnal Sains Farmasi \& Klinis, 7(1): 76-82. https://doi.org/10.25077/jsfk.7.1.76-82.2020

Fitri, A. C. K., \& Widyastuti, F. K. (2020). Perbandingan Metode Microwave Hydrodiffusion and Gravity (MHG) dan Microwave Steam Diffusion (MSDf) untuk Mengekstrak Minyak Atsiri dari Kulit Jeruk (Citrus aurantium L.). Jurnal Teknik Kimia USU, 9(2). https:// doi.org/10.32734/jtk.v9i2.4302
Forli, S., Huey, R., Pique, M. E., Sanner, M. F., Goodsell, D. S., \& Olson, A. J. (2016). Computational protein-ligand docking and virtual drug screening with the AutoDock suite. Nature Protocols, 11(5), 905-919. https://doi.org/10.1038/nprot.2016.051

Ganceviciene, R., Liakou, A. I., Theodoridis, A., Makrantonaki, E., \& Zouboulis, C. C. (2012). Skin antiaging strategies. In Dermato-Endocrinology, 4(3): 308-319. https://doi.org/10.4161/derm.22804

Gómez-Mejía, E., Rosales-Conrado, N., LeónGonzález, M. E., \& Madrid, Y. (2019). Citrus peels waste as a source of value-added compounds: Extraction and quantification of bioactive polyphenols. Food Chemistry, 295: 289-299. https://doi.org/10.1016/j. foodchem.2019.05.136

Han, Y., Zhang, J., Hu, C. Q., Zhang, X., Ma, B., \& Zhang, P. (2019). In silico ADME and toxicity prediction of ceftazidime and its impurities. Frontiers in Pharmacology, 10: 434. https://doi.org/10.3389/ fphar.2019.00434

Kim, S., Chen, J., Cheng, T., Gindulyte, A., He, J., He, S., Li, Q., Shoemaker, B. A., Thiessen, P.A., Yu, B., Zaslavsky, L., Zhang, J., \& Bolton, E. E. (2021). PubChem in 2021: new data content and improved web interfaces. Nucleic Acids Research, 49(1): 1388-1395. https://doi.org/10.1093/nar/gkaa971

Lv, X., Zhao, S., Ning, Z., Zeng, H., Shu, Y., Tao, O., Xiao, C., Lu, C., \& Liu, Y. (2015). Citrus fruits as a treasure trove of active natural metabolites that potentially provide benefits for human health. In Chemistry Central Journal, 9: 68. https://doi.org/10.1186/s13065-0150145-9

M'hiri, N., Ioannou, I., Ghoul, M., \& Mihoubi Boudhrioua, N. (2017). Phytochemical characteristics of citrus peel and effect of conventional and nonconventional processing on phenolic compounds: A review. In Food Reviews International, 33(6). https://doi.org/10.1080/87 559129.2016.1196489

Mobley, D. L., \& Klimovich, P. V. (2012). Perspective: Alchemical free energy calculations for drug discovery. In Journal of Chemical Physics, 137(23): 230901. https://doi.org/10.1063/1.4769292

Muttaqin, F. Z., Fakih, T. M., \& Muhammad, H. N. (2017). Molecular docking, molecular dynamics, and in silico toxicity prediction studies of coumarin, N-Oxalylglycine, organoselenium, organosulfur, and pyridine derivatives as histone lysine demethylase inhibitors. Asian Journal of Pharmaceutical and Clinical Research, 10(12): 212. 
https://doi.org/10.22159/ajpcr.2017.v10i12.19348

Osorio, E., Bravo, K., Cardona, W., Yepes, A., Osorio, E. H., \& Coa, J. C. (2019). Antiaging activity, molecular docking, and prediction of percutaneous absorption parameters of quinoline-hydrazone hybrids. Medicinal Chemistry Research, 28(11). https://doi.org/10.1007/ s00044-019-02427-0

Pitaloka, D. A. E., Ramadhan, D. S. F., Arfan, Chaidir, L., \& Fakih, T. M. (2021). Docking-based virtual screening and molecular dynamics simulations of quercetin analogs as enoyl-acyl carrier protein reductase (Inha) inhibitors of mycobacterium tuberculosis. Scientia Pharmaceutica, 89(2): 20. https://doi.org/10.3390/scipharm89020020

Rafiq, S., Kaul, R., Sofi, S. A., Bashir, N., Nazir, F., \& Ahmad Nayik, G. (2018). Citrus peel as a source of functional ingredient: A review. In Journal of the Saudi Society of Agricultural Sciences, 17(4): 351-358. https:// doi.org/10.1016/j.jssas.2016.07.006

Seitz, F., Bundschuh, M., Rosenfeldt, R. R., \& Schulz, R. (2013). Nanoparticle toxicity in Daphnia magna reproduction studies: The importance of test design. Aquatic Toxicology, 126: 163-168. https://doi. org/10.1016/j.aquatox.2012.10.015

Singh, J., Chopra, D., Dwivedi, A., \& Ray, R. S. (2018). Photoaging. In Photocarcinogenesis and Photoprotection. https://doi.org/10.1007/978-981-105493-8_ 7

Tauro, M., Laghezza, A., Loiodice, F., Piemontese, L., Caradonna, A., Capelli, D., Montanari, R., Pochetti, G., Di Pizio, A., Agamennone, M., Campestre, C., \& Tortorella, P. (2016). Catechol-based matrix metalloproteinase inhibitors with additional antioxidative activity. Journal of Enzyme Inhibition and Medicinal Chemistry, 31(sup4): 25-37. https://doi.org/10.1080/14756366.201 6.1217853

Thring, T. S. A., Hili, P., \& Naughton, D. P. (2009). Anticollagenase, anti-elastase and anti-oxidant activities of extracts from 21 plants. BMC Complementary and Alternative Medicine, 9: 27. https://doi. org/10.1186/1472-6882-9-27
Ugur, I., Marion, A., Parant, S., Jensen, J. H., \& Monard, G. (2014). Rationalization of the $\mathrm{p} \mathrm{K}$ a values of alcohols and thiols using atomic charge descriptors and its application to the prediction of amino acid $\mathrm{p} \mathrm{K}$ a's. Journal of Chemical Information and Modeling, 54(8): 2200-2213. https://doi.org/10.1021/ci500079w

Vijayakumar, R., Gani, S. S. A., \& Mokhtar, N. F. (2017). Anti-elastase, anti-collagenase and antimicrobial activities of the underutilized red pitaya peel: An in vitro study for antiaging applications. Asian Journal of Pharmaceutical and Clinical Research, 10(8): 251. https://doi.org/10.22159/ajpcr.2017.v10i8.19048

Von Nussbaum, F., Li, V. M., Meibom, D., Anlauf, S., Bechem, M., Delbeck, M., Gerisch, M., Harrenga, A., Karthaus, D., Lang, D., Lustig, K., Mittendorf, J., Schäfer, M., Schäfer, S., \& Schamberger, J. (2016). Potent and Selective Human Neutrophil Elastase Inhibitors with Novel Equatorial Ring Topology: In vivo Efficacy of the Polar Pyrimidopyridazine BAY8040 in a Pulmonary Arterial Hypertension Rat Model. ChemMedChem, 11(2): 199-206. https://doi. org/10.1002/cmdc.201500269

Xu, R. R., Pei, Z. T., Wang, W. Q., Zhang, M., Zhang, L. L., Zhang, J., Wang, W. Q., Sun, L. W., \& Zhang, Y. M. (2020). Assessment of biological toxicity and ecological safety for urban black-odor river remediation. International Journal of Environmental Research and Public Health, 17(3): 1025. https://doi.org/10.3390/ ijerph17031025

Zhu, K., Borrelli, K. W., Greenwood, J. R., Day, T., Abel, R., Farid, R. S., \& Harder, E. (2014). Docking covalent inhibitors: A parameter free approach to pose prediction and scoring. Journal of Chemical Information and Modeling, 54(7): 1932-1940. https://doi.org/10.1021/ ci500118s 